\title{
ANALOGIA ENTRE ADMINISTRAÇÃO CONTÁBIL E SUSTENTABILIDADE AMBIENTAL
}

\author{
Anderson Alves Santos ${ }^{1}$ \\ Aurélio Ferreira Borges ${ }^{2}$ \\ José Luiz Pereira de Rezende ${ }^{3}$ \\ José Aldo Alves Pereira ${ }^{4}$
}

Resumo: O objetivo desta pesquisa é descrever aspectos que envolvem as organizações que buscam alcançar a eficiência ambiental de suas atividades. Utilizou-se da contabilidade ambiental como metodologia de promoção do desenvolvimento sustentável baseando-se no tripé da igualdade social, da viabilidade econômica e da assistência ambiental, colunas da sustentabilidade ambiental. A pesquisa buscou divulgar porque a contabilidade atua nas organizações, dirigindo-se ao desenvolvimento sustentável, mais à frente do emprego do marketing verde como desenho de difusão das finalidades dessas organizações em disseminar seus programas de acréscimos sociais, ambientais e econômicos.

Palavras-chave: contabilidade; marketing verde; desenvolvimento sustentável.

\section{Introdução}

A preocupação com a preservação ambiental, quando utilizada como instrumento de valorização da empresa, está em franco crescimento, devido à necessidade que estas têm de alavancarem sua imagem perante os consumidores. As empresas de um modo geral estão se tornando mais sensíveis às reivindicações impostas pela sociedade e pelo mercado. $O$ pensamento de preservação ambiental - utilizado pelo marketing verde como fator de promoção - não é o único fator de diferenciação no mercado. Nessa busca, muitas metodologias e ferramentas têm sido utilizadas, umas com mais sucesso, outras nem tanto.

\footnotetext{
${ }^{1}$ Instituto Federal de Educação, Ciência e Tecnologia de Minas Gerais, Campus Formiga.

E-mail: alvessanto@gmail.com

${ }^{2}$ Instituto Federal de Educação, Ciência e Tecnologia de Rondônia, Campus Colorado do Oeste.

E-mail: aferreiraborges@gmail.com.

${ }^{3}$ Universidade Federal de Lavras. E-mail: jlprezen@dcf.ufla.br.

${ }^{4}$ Universidade Federal de Lavras. E-mail j.aldo@dcf.ufla.br.
}

Revbea, São Paulo, V.9, N² 2: 287-299, 2014. 
É necessário encontrar ferramentas adequadas que possam promover a imagem da empresa e, ao mesmo tempo, realçar seus ativos ambientais, objetivando garantir uma melhor posição mercadológica e alcançar respeito socioambiental perante os acionistas da empresa.

Nesse aspecto, uma das melhores opções é a contabilidade ambiental, como forma de promoção do desenvolvimento sustentável. Os reflexos percebidos nesse processo de interação e ajuste entre a contabilidade ambiental e o desenvolvimento sustentável fazem com que a organização tenha maiores chances de alcançar um grau de diferenciação mais elevado, tornado as empresas mais competitivas por produzir não apenas receitas econômicas, mais principalmente, dividendos socioambientais. Daí a importância de se discutir a questão ambiental nas empresas.

A temática ambiental se faz presente mercadologicamente há, relativamente, pouco tempo. Teve início em 1972, quando aconteceu a Primeira Conferência sobre o assunto em Estocolmo, na Suécia. Depois vieram as Conferências do Rio (ECO92), Rio +5, Rio +10, e o Protocolo de Kioto. É recente a consolidação dos aspectos ambientais como fator de diferenciação organizacional, implicando, assim, em uma apresentação dos ativos e, ou passivos ambientais realizados pela contabilidade ambiental.

Antes de ser uma forma de mostrar que a organização está "boa das pernas", a contabilidade é uma exigência legal. Na forma atual de negociação mundial, globalizada, não se cogita uma transação (monetária ou mercadológica) sem levar em conta as necessidades sociais, econômicas, ambientais, objetivando a melhoria de qualidade de vida, sem uma busca de empatia entre a contabilidade e o desenvolvimento sustentável. O meio ambiente era pensado, a princípio, somente por pessoas com ideologias de preservação ambiental e mesmo assim, a conotação dada aos recursos naturais relacionava-se, basicamente, as suas belezas cênicas naturais, sem haver muita preocupação com o equilíbrio ecológico.

Atualmente percebe-se uma preocupação maior em relação ao tema ambiental, visto que todas as áreas da economia - Bancos, Empresas, Organizações Não Governamentais (Ongs), organizações diversas, Bolsas de Valores, entre outras - tenham atenção voltada à questão ambiental, ou melhor, aos impactos negativos causados pelas organizações ao meio ambiente. Então, os recursos naturais passaram a ter importância na gestão das organizações, visto que sua inter-relação com a espécie humana é de importância fundamental para a continuidade da vida, não apenas do ser humano, mas do planeta como um todo. Tal preocupação pode ser observada sob vários aspectos, como por exemplo: sequestro de gás carbônico, geoprocessamento para exploração mineral, aumento da quantidade de Ongs ambientais, quantidade de documentários sobre o assunto e, principalmente, em financiamentos e acordos de cooperação internacionais que visam a desenvolver modelos de uso racional dos recursos naturais.

De acordo com Tinoco (2004), por muito tempo as organizações Revbea, São Paulo, V V.9, N²: 287-299, 2014. 
preocuparam-se com os métodos de produtividade, não se dando muita importância ao meio ambiente como um todo. O crescimento da consciência econômica, transformando o modo de pensar e agir da sociedade, do governo e das empresas por informações ambientais na Contabilidade e ações de gestão ambiental para prevenir e corrigir danos, ficou evidente a partir de um pensamento não cartesiano, relacionado às questões ambientais, entendidas como passivo ambiental.

O passivo ambiental, em termos contábeis, são as obrigações das empresas para com terceiros, sendo que tais obrigações, mesmo sem uma cobrança formal ou legal, devem ser reconhecidas. O passivo ambiental representa os danos causados ao meio ambiente pelas ações antrópicas, representando, assim, a obrigação ou a responsabilidade social da empresa com os aspectos ambientais. Dessa forma, várias perguntas que embora se apresentem de forma evidente, ainda não foram respondidas, como por exemplo: como contabilizar o meio ambiente de uma gruta ou de uma reserva natural? Se houver resposta para a pergunta anterior quem deve pagar? A sociedade (mais uma vez) ou o Poder Público? Pagar a quem, visto que o prejuízo é global? Essas são apenas pequenas amostras das dúvidas de que todos os habitantes da Terra devem buscar a resposta antes que seja tarde demais, para se entender as respostas de tais indagações e agir.

Sabe-se que enfrentar a desigualdade de renda baseada no crescimento tem se mostrado tarefa árdua, pois passa, necessariamente, pela ampliação de oportunidades e pelo acesso à riqueza. $O$ homem consolida sua posição sobre os meios de produção e o capital, efetivando, desta forma, o domínio técnico e científico sobre o meio ambiente. Muitos aperfeiçoamentos tecnológicos foram conquistados, mas mudanças mais radicais só viriam impactar, decisivamente, a humanidade com a acumulação do conhecimento e sua ampla difusão no período pós-industrial.

Deve-se assumir que o local, onde homem habita, trabalha e cria suas famílias - o planeta Terra - é um espaço diferenciado, seja ele público ou privado. Este espaço deve ser percebido como um ambiente privilegiado para execução de políticas ativas de promoção do desenvolvimento econômico, social e ambiental. Dada a urgência por novos modelos de construção de políticas públicas de promoção do desenvolvimento e geração de riqueza, torna-se cada vez mais necessário que governo e iniciativa privada sejam capazes de captar e refletir sobre as diferentes dinâmicas produtivas dos diversos locus.

Mesmo com o aperfeiçoamento das invenções e o domínio técnicocientífico, talvez o essencial tenha passado ao largo: o entendimento de que todo espaço requer uma lógica de produção sustentável para que a exploração de recursos, produção de bens e a geração e distribuição de riqueza sejam também sustentáveis e combine redução da desigualdade com crescimento econômico. Os governos precisam respeitar a lógica desse entendimento e desenvolver estratégias e políticas de desenvolvimento específicas a cada contexto. 
O objetivo da pesquisa é descrever as organizações que objetivam alcançar o desenvolvimento sustentável, com base no tripé da sustentabilidade - justiça social, viabilidade econômica e ética ecológica - e na contabilidade ambiental, como forma para alcançar a eficiência ambiental em suas atividades.

Problema de pesquisa: como estão classificadas as organizações que objetivam alcançar o desenvolvimento sustentável, com base no tripé da sustentabilidade, justiça social, viabilidade econômica e da ética ecológica?

\section{Desenvolvimento Sustentável}

O desenvolvimento sustentável é um paradigma de desenvolvimento surgido a partir das discussões, nas décadas de 70 e 80 do século XX, sobre os limites do crescimento da população humana, da economia e da utilização dos recursos naturais. Ele procura integrar e harmonizar as ideias e conceitos relacionados ao crescimento econômico com a justiça, o bem- estar social, a conservação ambiental e a utilização racional dos recursos naturais. Para tanto, considera-se as dimensões social, ambiental, econômica e institucional do desenvolvimento, conforme entendimento do Relatório Brundtland.

O termo Desenvolvimento Sustentável surgiu em 1980, na publicação "World Conservation Strategy: living resource conservation for sustainable development", elaborado pela International Union for Conservation of Nature and Natural Resources (IUCN), em colaboração com o Programa das Nações Unidas para o Meio Ambiente (PNUMA) e outras instituições internacionais. Ainda não foi alcançado um consenso sobre seu conceito, que tem se modificado muito rapidamente, estando em contínua construção. De acordo com Goldsmith et al. (1972), uma sociedade somente poderá ser considerada sustentável quando todos os seus propósitos e intenções puderem ser atendidos indefinidamente, alcançando um nível de satisfação ótimo e contínuo para seus membros.

Em termos sociais, o desenvolvimento sustentável propõe uma repartição mais justa das riquezas produzidas (justiça social), a universalização do acesso à educação e à saúde, e a equidade entre sexos, grupos étnicos, sociais e religiosos, entre outros aspectos. Para que seja sustentável, o desenvolvimento significa melhoria na qualidade de vida de toda a população, assegurando condições de vida dignas a todos e garantindo a justiça social. Do ponto de vista ambiental, o desenvolvimento sustentável propõe a utilização parcimoniosa dos recursos naturais, com o intuito de garantir seu uso pelas gerações futuras. Para tal, propõe que os recursos naturais renováveis sejam usados aquém de sua capacidade de renovação, e os não renováveis de forma pensada, permitindo o seu uso pelo máximo de tempo e de gerações possível. Propõe, ainda, a preservação de amostras significativas do ambiente natural, de forma a garantir a manutenção dos serviços ambientais que estas áreas propiciam e a qualidade de vida da população do entorno. Uma das características deste novo paradigma de desenvolvimento é o compromisso e a Revbea, São Paulo, V V.9, Nº 2: 287-299, 2014. 
preocupação com as condições de vida das próximas gerações.

Dessa forma, Sachs (1997) percebe que a sustentabilidade social refere-se a um processo de desenvolvimento que possa levar a um crescimento estável com uma distribuição equitativa de renda, gerando a diminuição das diferenças atuais entre os diversos níveis da sociedade e a melhoria das condições de vida das diversas populações.

Quanto à economia, o desenvolvimento sustentável postula o crescimento baseado no aumento da eficiência de uso da energia e dos recursos naturais. $O$ desenvolvimento sustentável postula também mudanças nos padrões de consumo da sociedade e nos padrões de produção, com a redução do desperdício e maior consciência dos impactos causados pelo uso dos recursos naturais. Observado pelo campo institucional, o desenvolvimento sustentável avalia o grau de participação e controle da sociedade sobre as instituições públicas e privadas, o aparelhamento do estado para lidar com as questões ambientais, o envolvimento em acordos internacionais, o montante de investimento em proteção ao meio ambiente, ciência e tecnologia e o acesso a novas tecnologias.

A dimensão institucional trata da orientação política, da capacidade e do esforço despendido pela sociedade, para que sejam realizadas as mudanças necessárias para a efetivação deste novo paradigma de desenvolvimento. Neste novo paradigma, a palavra desenvolvimento leva em conta não apenas o crescimento da atividade econômica, mas também as melhorias sociais, institucionais e a sustentabilidade ambiental, buscando, em última análise, garantir o bem estar da população em longo prazo, assegurando um meio ambiente saudável para as futuras gerações.

A relação entre desenvolvimento e meio ambiente é considerada um ponto central para a compreensão dos problemas ecológicos. O conceito de desenvolvimento sustentável - entre os vários existentes - trata de uma nova forma da sociedade se relacionar com seu meio ambiente, garantindo sua própria continuidade (sobrevivência da espécie humana, principalmente) e a do meio externo. Meio ambiente corresponde não só ao meio físico e biológico, mas também ao meio sociocultural e sua relação com os modelos de desenvolvimento adotados pelo homem, que condicionam a existência dos seres vivos; portanto, não é o espaço onde se vive ou possa existir vida, mas o conjunto de condições que justificam a sua existência da Terra; assim, a intervenção antrópica sobre os recursos naturais pode ocasionar mudanças significativas no meio ambiente. Estes impactos são resultantes do uso indiscriminado das fontes naturais para a produção de bens e serviços.

Em termos ecológicos, tem-se poluído mais o ar, contaminado mais os mares e extinguido mais espécies que em qualquer outra época. Nunca na história da humanidade o ser humano mostrou-se tão destruidor quanto nos últimos trezentos anos. A ciência e a tecnologia, em seu desenvolvimento desenfreado - não de todo negativo -, criaram diversos riscos: químicos, tecnológicos, nucleares, os quais não têm comparação com outros períodos da 
história da humanidade. Percebe-se o efeito destes avanços perigosos da ciência e da tecnologia nas cidades em desenvolvimento, onde o nível de contaminação e degradação ambiental é extremamente grande.

Os atos humanos têm provocado grandes perturbações nos ecossistemas, como a perda da biodiversidade, a super-exploração das reservas de água doce (inclusive dos lençóis freáticos) e a desestabilização dos ecossistemas que provocam, muitas vezes, danos irreversíveis. A cada dia são produzidos mais e mais resíduos tóxicos e lixo, os quais não são reciclados totalmente ou em muitos casos, são jogados a esmo na natureza, sem o devido tratamento.

O ser humano tornou-se escravo de seus próprios inventos. O Homo faber deixou de ser apenas um produtor, de criar: tornou-se dependente destas produções e criações. Um exemplo desta escravidão é a dependência que se tem do automóvel. As pessoas que não o têm buscam adquiri-lo o mais breve possível, juntando suas economias para comprar o seu. Este fato faz com que as cidades entrem em colapso, pois o acúmulo de automóveis transforma o ar urbano num depósito de gás carbônico e agride seus moradores com níveis de ruído acima do suportável, além do estresse causado no trânsito.

Em algumas cidades, muitos ecossistemas foram suprimidos para darem lugar a imponentes construções ou bairros planejados para poucos morarem, ou para dar lugar a construções desordenadas de pessoas que, não tendo para onde ir, invadem espaços de terra sem levar em consideração toda a formação ecossistêmica do mesmo.

Os desequilíbrios ecológicos, com o passar do tempo, vão se tornando mais prejudiciais, pois são, cada vez mais, agravados pelo desequilíbrio social, que vão se constituindo em outra face dos problemas ambientais. A população cresceu verticalmente nas últimas décadas, porém o acesso aos recursos, tanto econômicos, quanto sociais, ambientais e/ou culturais não foram democratizados. Há uma má distribuição de recursos e do acesso aos mesmos. As diferenças Norte-Sul continuaram a aumentar e consequentemente trazendo mais pobreza e miséria aos países do Hemisfério Sul, denominados países periféricos ou em desenvolvimento. Vive-se numa economia globalizada, dominada por empresas transnacionais que não possuem objetivos democráticos, mas somente a expansão de seus capitais e lucros, pouco se importando com os problemas ambientais que venham a causar, principalmente em países do Terceiro Mundo, onde sua ação exploratória é percebida mais claramente.

Mas este quadro passa por uma mudança, ocasionada pelo chamado "marketing verde" ou marketing ambiental, que é responsável por dar forma à política ambiental da organização, auxiliando-a a aperfeiçoar e a programar seu aperfeiçoamento, integrado a um Sistema de Gestão Ambiental (SGA). É, também, uma ferramenta com capacidade de projetar e sustentar a imagem da organização, difundindo-a com uma nova visão de mercado, destacando sua diferenciação ecologicamente correta junto aos acionistas e ao mercado. $O$ 
marketing ambiental extrapola a publicidade ou divulgação dos produtos ou serviços oferecidos por empresas; ele é uma adoção ampla e real de políticas ambientais que vão desde a coleta da matéria-prima até sua disposição final. Envolve desde a área de recursos humanos, ciência e tecnologia, educação e tudo que estiver relacionado com a produção ou a prestação de serviços.

O marketing verde não se limita à promoção de produtos que tenham alguns atributos ditos 'verdes', como por exemplo, recicláveis e produtos que não ataquem a camada de ozônio. Isso acontece porque, para posicionar-se como responsável ambientalmente, a organização deve, antes de qualquer coisa, organizar-se para ser ambientalmente responsável em todas as suas atividades. Além disso, a organização deve adotar um comportamento próativa, ou seja, deve estar sempre aperfeiçoando seu comportamento ambiental, pois as expectativas dos consumidores estão em constante mudança.

O homem está no meio de uma crise ambiental e tem como certo que não sairá dela utilizando os mesmos modelos de desenvolvimento que lá os fez chegar. Precisa-se de um novo paradigma ambiental que leve à criação de novas relações homem/natureza e a novas relações entre os países do Norte (mais ricos) e os países do Sul (mais pobres). Precisa-se, também de novas relações homem/homem, onde os valores éticos sejam os condutores deste novo paradigma nas mudanças de relação. Precisa-se administrar um novo modelo de desenvolvimento em que pese à consideração de sustentabilidade das sociedades e que observe os limites dos ecossistemas ambientais e dos recursos naturais. Um novo paradigma que leve em consideração todas as necessidades do ser humano para se realizar como ser neste mundo.

\section{Fonte de Recursos}

A produção de bens e serviços que atendam às necessidades e aos desejos do ser humano, de acordo com Barbieri (2004), requer recursos ou fatores de produção e, dentre estes, o trabalho e os recursos naturais sempre estiveram presentes em todas as épocas. Ainda conforme o mesmo autor, os recursos naturais são bens e serviços originais, dos quais todos os demais seres dependem. Assim, pode-se dizer que produzir é converter ou transformar bens e serviços naturais para satisfazer as necessidades e os desejos humanos. Para melhor visualização, observe a divisão dos recursos naturais (Figura 1).

Os recursos renováveis podem ser entendidos como aqueles que podem ser obtidos indefinidamente por uma mesma fonte, enquanto os não renováveis possuem uma quantidade finita, que se esgotará se for explorada continuamente, sem nenhum planejamento. Na verdade, todos os recursos são renováveis por meio de ciclos naturais, embora alguns possam levar até milhões de anos, o que é impensável para o padrão humano de tempo. 


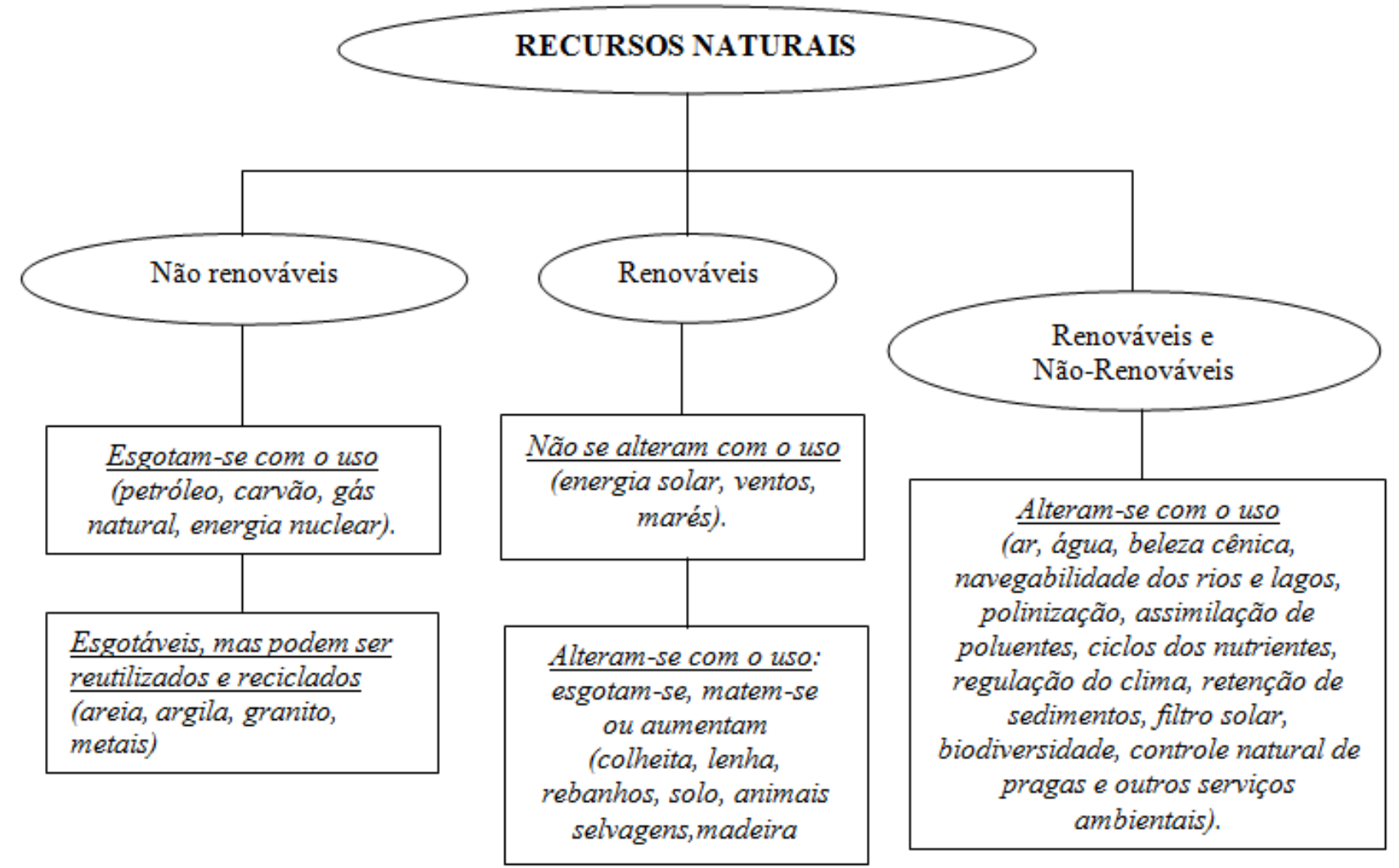

Figura 1: Divisão dos recursos naturais. Fonte: Adaptado de Tivy e O’Hare (1981)

\section{Sistema de Gestão Ambiental}

De acordo com Moreira (2001), dentro da área mercadológica e/ou administrativa, quando se busca uma minimização dos impactos ambientais, utiliza-se a ISO 14000, que tem como objetivo geral fornecer assistência para as organizações na implantação ou no aprimoramento de um Sistema de Gestão Ambiental (SGA). Ela é consistente com a meta de "Desenvolvimento Sustentável" e é compatível com diferentes estruturas culturais, sociais e organizacionais.

Um SGA "trabalha" em cima de dois fatores: Ativo Ambiental e Passivo Ambiental. $O$ ativo ambiental compreende todas as ações que a organização desenvolve em prol da conservação do ambiente, como por exemplo, a própria aplicação do SGA (que além de tornar a organização competitiva, evita diversos tipos de multas pela Legislação Ambiental). O Passivo Ambiental, conforme a percepção de Tachizawa et al. (2002) mostra os danos causados ao meio ambiente, representando, assim, a obrigação, a responsabilidade social da empresa com aspectos ambientais. Nessa proposta, no balanço

Revbea, São Paulo, V V.9, № 2: 287-299, 2014. 
patrimonial de uma empresa é incluído, por meio de cálculos estimativos, o passivo ambiental (danos ambientais gerados), e no ativo (bens e direitos), são incluídas as aplicações de recursos que objetivem a recuperação do ambiente, bem como investimentos em tecnologia de processos de contenção ou eliminação de poluição. A identificação do passivo ambiental está sendo muito utilizada em avaliações para negociações de empresas e em privatizações, pois a responsabilidade e a obrigação da restauração ambiental podem recair sobre os novos proprietários. Ele funciona como um elemento de decisão no sentido de identificar, avaliar e quantificar posições, custos e gastos ambientais potenciais que precisam ser atendidos. Deve ser ressaltado, porém, que o passivo ambiental não precisa estar diretamente vinculado aos balanços patrimoniais das empresas, podendo fazer parte de um relatório específico, discriminando-se as ações e esforços desenvolvidos para a eliminação ou redução de danos ambientais. Essa metodologia vem sendo seguida por empresas do mundo inteiro.

Conforme Tinoco (2004), o surgimento do comércio, que floresceu em cidades italianas das Idades Média e Moderna, contribuiu sobremaneira para o surgimento da Contabilidade, em base científica, passando pelos descobrimentos marítimos, empreendimentos nos quais os navegadores portugueses e espanhóis se envolveram, desembocando na Revolução industrial. Empreendida por ingleses, alemães e franceses nos séculos XVIII e XIX, a Revolução Industrial abriu novos horizontes para a humanidade, com a implantação da indústria em larga escala, bem como da ferrovia, inicialmente, e posteriormente outros meios de transporte. Integrou países e continentes (Europa), além de outros empreendimentos de porte, por sua complexidade, pelos capitais investidos, e pela demanda de informação exigiram e exigem uma Contabilidade que atenda basicamente aos interesses decisoriais de seus usuários, os stakeholders. Surge assim a necessidade de uma Contabilidade mais analítica e eficiente, não só meramente financeira, e o surgimento da Contabilidade Gerencial, voltada especialmente para fins internos, de atendimento ao processo decisório dos gestores empresariais.

A Contabilidade tem como finalidade prover os usuários das demonstrações contábeis com informações que os ajudarão a tomar decisões; os usuários se dividem em Internos (administradores, gerentes e acionistas) e Externos (investidores, fornecedores de bens e serviços, bancos, governo e sindicatos). As ferramentas tradicionais param se medir custo e capitais têm falhado por negligenciar, de um lado, a escassez provocada pela utilização desmedida dos recursos naturais, prejudicando a produção sustentável da economia e, de outro lado, a degradação da qualidade ambiental e as consequências desta sobre a saúde e bem-estar do ser humano.

De acordo com Dally (1992), a teoria econômica deve atender a três principais objetivos: alocação, escala e distribuição. Ressalta-se que alocação se refere à divisão relativa dos fluxos de recursos; a distribuição está relacionada à divisão dos recursos entre as pessoas e a escala se refere ao volume físico do fluxo de matéria e energia. Na economia moderna, as 
questões relativas à alocação e distribuição apresentam um tratamento consistente tanto em termos teóricos quanto históricos. No entanto, a questão que diz respeito à escala ainda não é formalmente reconhecida e não conta com instrumentos políticos de execução. Uma boa alocação refere-se àquela que disponibiliza recursos em função das preferências individuais. Daí a importância da contabilidade ambiental.

\section{Contabilidade Ambiental}

Conforme Zanluca (2007), a contabilidade apresenta sua forma sistemática de registro e controle, contribuindo de forma positiva no campo de proteção ambiental, por meio de dados econômicos e financeiros resultantes das organizações que exploram o meio ambiente. O conjunto de informações é denominado de "contabilidade ambiental" que significa registro do patrimônio ambiental (bens, direitos e obrigações ambientais), e suas respectivas mutações - expressos monetariamente.

De acordo com Paiva (2003), a relação do homem com o meio ambiente, tanto na forma de nação ou entidade, designou o termo Contabilidade Ambiental, que se propõe ao registro e geração de relatórios para auxiliar na elaboração do planejamento estratégico, bem como servir de parâmetro no gerenciamento das atividades-alvo e fornecer informações externas para a prestação de contas dessas atividades.

O objetivo da contabilidade ambiental é propiciar informações regulares aos usuários internos e externos de acordo com os eventos ambientais que causaram alterações na situação patrimonial da respectiva organização, quantificado em moeda. Conforme Ribeiro e Lisboa (1999), essas informações podem ser identificadas mediante: os estoques de insumos antipoluentes para inserção no processo operacional; os investimentos realizados em tecnologias antipoluentes (equipamentos, instalações); o montante de obrigações assumidas pela empresa no sentido de recuperação de áreas degradadas ou águas contaminadas, bem como para pagamento de penalidades ou multas decorrentes de infrações à legislação ambiental; as reservas para contingências constituídas com base na probabilidade de ocorrência de perdas patrimoniais provocadas por eventos de natureza ambiental; o montante de custos e despesas incorridos objetivando a contenção dos níveis de poluição e/ou por penalidades recebidas por procedimentos inadequados.

A contabilidade se constitui em uma enorme fonte de registro, interpretação e informação de dados tanto empresariais quanto governamentais. De acordo com Kraemer (2007) ela se presta também como utilidade social, como foi divulgada por Jacques Chirac, ex-presidente da França, quando discursou na sessão plenária de encerramento do XV Congresso Mundial de Contadores, em 1997, afirmando que a profissão contábil desempenha um papel fundamental na modernização e internacionalização de nossa economia. Isso porque ela não se restringe em cuidar somente de registros contábeis. A contabilidade é conselheira e, às Revbea, São Paulo, V V.9, Nº 2: 287-299, 2014. 
vezes, confidente das administrações de companhias, para que tem importante papel a desempenhar, especialmente em assuntos sociais e tributários. A contabilidade orienta pequenas e médias empresas e sua administração, simplificando as alternativas que ainda são demasiadamente complexas.

Devido ao aumento crescente de uso de recursos naturais e da degradação da natureza, a escassez desses em todo o mundo aprofundou tanto o debate econômico, quanto político e social a respeito desta escassez e sobre as medidas necessárias para reversão desta situação. Por isso a necessidade de se ter conhecimento do problema, não apenas sob o aspecto mais amplo, mas também sobre aspectos específicos, tais como saber que boa parte da degradação ambiental acontece em decorrência das próprias formas de produção, de recursos finitos.

Como o mercado não vê possibilidade de reverter o progresso - e isso não é desejável, pois os sistemas econômicos necessitam atender à demanda de bilhões de pessoas do planeta terra - faz-se necessário encontrar respostas às tais questões mediante um amplo e contínuo trabalho de aferição dos eventos ambientais tanto por governos, entidades privadas, quanto por Ongs. Daí a importância da contabilidade como ciência, que tem a vantagem de oferecer meios de aferição econômica de tais políticas.

A utilização irresponsável dos meios naturais para a produção de bens e serviços, além dos danos ambientais óbvios que causa, tende a gerar, para a entidade que o provocou, o repúdio da sociedade e dos consumidores. Dessa forma, economicamente, a gestão ambiental não precisa ser entendida como "um custo a mais", mas sim, como uma excelente oportunidade de demonstrar responsabilidade social e melhorar a imagem mercadológica da organização, gerando um vantajoso ciclo de lucros sustentáveis a médio e longo prazo.

Para se tomar decisões e promover a avaliação regular de políticas ambientais, a contabilidade é fundamental, pois gera informações relevantes aos administradores de qualquer entidade. De acordo com Zanluca (2007) podem ser citadas as seguintes vantagens da utilização da contabilidade ambiental para a organização: Identificação e alocação de custos ambientais, de maneira que as decisões de investimentos sejam tomadas com base em custos e benefícios adequadamente medidos; Permissão para aferir, economicamente, as reduções de gastos com água, energia e outros recursos, renováveis ou não; geração de informações e demonstrativos sobre a eficácia e viabilidade econômica das ações ambientais; a publicação do balanço ambiental gera transparência da gestão e melhora a imagem da entidade produtora junto ao mercado e, principalmente, junto aos consumidores; Contribuição contínua para a correção das ações ambientais, em decorrência da utilização de dados físico-contábeis, para a sociedade como um todo; Ganho para a sociedade com a redução do nível de agressão à natureza na elaboração de produtos e serviços indispensáveis.

Existem diferentes percepções acerca da contabilidade gerencial em relação à ambiental. Na gerencial, por exemplo, há uma orientação maior para 
tomada de decisão dentro da organização, enquanto na ambiental o foco é centrado em balanços de massa e na informação do custo ambiental. A contabilidade ambiental demonstra o passivo ambiental, o qual tem impacto econômico financeiro no valor final dos produtos e serviços de determinada organização e no valor de mercado da própria organização (Tabela1).

Tabela 1: Diferença entre a Contabilidade Gerencial e a Contabilidade Ambiental.

\begin{tabular}{|c|c|}
\hline Tipos de Contabilidade & Paralela ambiental da contabilidade \\
\hline $\begin{array}{l}\text { Contabilidade Gerencial } \\
\text { A identificação, a estimação, a análise e uso } \\
\text { do custo e de informações para a tomada de } \\
\text { decisão dentro de uma organização. }\end{array}$ & $\begin{array}{l}\text { Contabilidade Gerencial Ambiental } \\
\text { Contabilidade de gestão com foco centrado } \\
\text { em balanços de massa, em fluxos de } \\
\text { materiais, fluxo de energia e na informação do } \\
\text { custo ambiental. }\end{array}$ \\
\hline $\begin{array}{l}\text { Contabilidade Financeira } \\
\text { Elaboração e divulgação de relatórios } \\
\text { contábeis e financeiros, de uma organização } \\
\text { aos usuários externos (por exemplo, } \\
\text { acionistas, fornecedores, bancos, governo, } \\
\text { comunidade etc.). }\end{array}$ & $\begin{array}{l}\text { Contabilidade Financeira Ambiental } \\
\text { Contabilidade financeira com o foco particular } \\
\text { em relatar custos, despesas e passivos } \\
\text { ambientais da responsabilidade empresarial e } \\
\text { outras questões ambientais significativas. }\end{array}$ \\
\hline $\begin{array}{l}\text { Contabilidade Nacional } \\
\text { Desenvolvimento de informações diversas } \\
\text { (econômicas e outras) para caracterizar a } \\
\text { renda nacional e a saúde econômica. }\end{array}$ & $\begin{array}{l}\text { Contabilidade Nacional Ambiental } \\
\text { Contabilidade nacional com foco particular no } \\
\text { estoque e nos fluxos de recursos naturais, em } \\
\text { custos ambientais, em custos de } \\
\text { externalidade. }\end{array}$ \\
\hline
\end{tabular}

Fonte: Adaptado de Tinoco (2004).

A Contabilidade Ambiental pode ser adaptada a qualquer tipo de organização industrial ou de transformação e até mesmo de prestação de serviço.

\section{Conclusões}

O objetivo da contabilidade ambiental é propiciar informações regulares a todos os usuários dos produtos da respectiva organização, de acordo com os eventos ambientais que causam alterações na situação patrimonial da mesma, aliado a uma visão preservacionista.

A incorporação da contabilidade ambiental no planejamento estratégico das organizações visa à melhoria do desempenho ambiental das mesmas, pois o mercado não mais aceita o descaso no tratamento dos recursos naturais e os consumidores estão interessados em produtos 'limpos', o que influencia as organizações a encarar com seriedade e responsabilidade a variável ambiental em sua estratégia operacional.

É importante que se tenha um fator de medição dos impactos

tais, para que se possa almejar o desenvolvimento sustentável - apesar 
A contabilidade ambiental não se presta apenas à controladoria econômica das organizações; ela tem ramificações sociais também. É claro que fatores políticos tanto quanto da economia mundial moderna influenciam no pronto estabelecimento de um desenvolvimento de mínima entropia.

Usando a contabilidade ambiental como um possível indicador de sustentabilidade socioambiental, perceber-se-ia um aumento da responsabilidade ambiental das diversas organizações empresariais mundiais no uso dos recursos naturais, objetivando um ganho de capital real, e não apenas o uso e divulgação de seus balanços finais.

\section{Agradecimentos}

Os autores agradecem à Universidade Federal de Lavras (UFLA), por tornar possível o pós-doutoramento do $1^{\circ}$ e do $2^{\circ}$ autores.

\section{Referências}

BARBIERI, J. C. Gestão ambiental empresarial: conceitos, modelos e instrumentos. São Paulo: Saraiva, 2004. 328 p.: il.

GOLDSMITH, E. et al. Blueprint for survival. Boston: Penguin, Harmondsworth \& Houghton Miflin, 1972.

KRAEMER, M.E.P. Contabilidade ambiental: relatório para um futuro sustentável, responsável e transparente. 2007. Disponível em: <http://www.ambientebrasil.com.br/contabilidade ambiental.html >. Acesso em: 04 nov. 2007.

MOREIRA, M.S. Estratégia e implantação do sistema de gestão ambiental: modelo iso 14000. BH: Editora de Desenvolvimento Gerencial, 2001, 288 p.: il.

PAIVA, P.R. Contabilidade ambiental: evidenciação dos gastos ambientais com transparência e focada na prevenção. São Paulo: Atlas, 2003.

SACHS, I. Desenvolvimento sustentável, bioindustrialização descentralizada e novas configurações rural-urbanas:os casos da índia e do brasil. São Paulo: Cortez, 1997.

TINOCO, J.E.P.; KRAEMER, M.E.P. Contabilidade e gestão ambiental. São Paulo: Atlas, 2004.

TIVY, J.; O'HARE, G. Human impact on the ecosystem: conceptual frameworks in geography. Edinburgh: Oliver \& Boyd, 1981.

ZANLUCA, J.C. 0 que é contabilidade ambiental? Disponível em: $<$ http://www.portaldecontabilidade.com.br/tematicas/contabilidadea mbiental.htm/>. 2007. Acesso em: 07 abri 2007. 